\title{
CCongresso Internacionaldas
}

\section{MORFOLOGIA DE PLÂNTULAS DE Enterolobium contortisiliquum (Vell.) Morong}

\author{
Apresentação: Comunicação Oral
}

Sarah Patrícia Lima Nunes ${ }^{1}$; Ana Luiza da Silva Lopes ${ }^{2}$; Josenilda Aprigio Dantas de Medeiros ${ }^{3}$ Maria Luiza de Lima Castro ${ }^{4}$; Mauro Vasconcelos Pacheco ${ }^{5}$

\section{Resumo}

A Caatinga exibe grande diferença fitofisionômica em virtude dos diferentes padrões de solo e irregularidade na precipitação, isso implica em um tipo de vegetação singular, sendo classificada como floresta arbórea arbustiva (adaptada ao clima semiárido), com ocorrência de cactos, bromélias e extrato herbáceo abundante durante a estação chuvosa, sendo assim, torna-se difícil identificar espécies vegetais ainda no estágio de plântula, neste período os aspectos morfológicos das primeiras fases de uma planta são pouco estudados e tendem a se sobrepor entres as espécies. Dentre as espécies com potencial de uso do bioma Caatinga, encontra-se a Enterolobium contortisiliquum, utilizada na recuperação de áreas degradadas, alimentação animal, produção de energia (lenha e carvão) e uso da madeira em construções navais e rurais. Objetivou-se nesse trabalho descrever morfologicamente as plântulas da espécie Enterolobium contortisiliquum. Para a descrição morfológica foi instalado o teste de germinação com semente de cinco lotes no sistema de rolos com papel tolha (tipo Germitest ${ }^{\circledR}$ ) e em bandejas com areia previamente lavada e esterilizada, utilizando 100 sementes em cada método. Foram realizadas observações diárias e registro de imagens para descrever todo o processo germinativo das sementes, desde a protrusão da raiz até o desenvolvimento dos eófilos. A emissão da raiz primária ocorreu no quarto dias após a semeadura, rompendo o tegumento na base da semente, próximo ao hilo; a raiz primaria mostrou-se com forma pivotante, de coloração amarelo claro e com poucos pelos simples. Os cotilédones emergem acima do nível do substrato. Logo em seguida, a partir do sétimo dia ocorreu o desprendimento do tegumento, deixando os cotilédones carnosos livres, caracterizando uma germinação epígea fanerocotiledonar. O hipocótilo é alongado e retilíneo, com coloração verde acinzentado amarelo claro. O epicótilo tem coloração verde acinzentado amarelo. Os eófilos são compostos, opostos, bipinados, possuem coloração verde acinzentado amarelo escuro. O desenvolvimento das plântulas foi uniforme, possibilitando o uso destes dados na identificação em campo e em testes laboratoriais com a espécie.

Palavras-Chave: Sementes florestais, Caatinga, Tamboril.

\footnotetext{
${ }^{1}$ Mestrado em Ciências Florestais, UAECIA/UFRN, sarahnunes17@hotmail.com

${ }^{2}$ Graduando em Engenharia Florestal, UAECIA/UFRN, analuizaslps@gmail.com

${ }^{3}$ Mestrado em Ciências Florestais, UAECIA/UFRN, josi-nilda@hotmail.com

${ }^{4}$ Graduando em Engenharia Florestal, UAECIA/UFRN, castro.luiza@hotmail.com

${ }^{5}$ Biólogo, Dr., Professor UAECIA/UFRN, pachecomv@hotmail.com
} 


\section{Introdução}

Pesquisas que tratam da morfologia de frutos, sementes e plântulas auxiliam na identificação de espécies e na interpretação de testes laboratoriais, as quais são parâmetros importantes para reconhecê-las botanicamente em banco de sementes no solo ou em formações florestais (MELO et al., 2004; PIMENTA, et al., 2013).

O bioma Caatinga exibe diferentes padrões no que se refere aos tipos de solos, precipitação e ocorrência de vegetação, os quais interferem diretamente na morfologia das espécies que ocorrem naturalmente na região. Assim, é importante que novos trabalhos que caracterizem as fases iniciais do crescimento de plântulas sejam realizados, a fim de complementar as informações existentes para estas espécies.

Dentro deste contexto, objetivou-se caracterizar plântulas de Enterolobium contortisiliquum quanto aos seus aspectos morfológicos.

\section{Fundamentação Teórica}

Devido à irregularidade na precipitação e aos diferentes modelos de solos, o bioma Caatinga apresenta distintas características fitofisionômicas (MMA, 2008), tornanso-se complexo identificar espécies vegetais na fase pós-seminal. As características morfológicas dos primeiros estágios de uma planta (plântulas) têm sido pouco estudadas em várias famílias (FEITOZA et al., 2014).

A plântula é um organismo vegetal desenvolvido a partir de semente, basicamente apresenta as seguintes estruturas: radícula; hipocótilo, cotilédone(s) e gema plumonar, que darão origem à raiz, caule e folhas (FERREIRA; BORGHETTI, 2004). Algumas espécies de Caatinga apresentam taxonomia similar na fase inicial do desenvolvimento, é uma tarefa complexa a identificação das mesmas levando em consideração que as espécies apresentam sobreposição de algumas características, sendo assim, os estudos morfológicos de plântulas são uma ferramenta para auxiliar na identificação e diferenciação das espécies existentes no bioma (QUEIROZ, 2009; MENDONÇA et al., 2016).

Estudos morfológicos relacionados a sementes e plântulas auxiliam na interpretação de testes laboratoriais, além de permitirem a identificação botânicas de espécies, sendo parâmetro importante para reconhecê-las em banco de sementes na fase de plântula ou em formações florestais (MELO et al., 2004; PIMENTA, et al., 2013).

A espécie Enterolobium contortisiliquum, é indicada para construções de embarcações, assoalhos e construções rurais (RIZZINI, 1978). É uma boa espécie para o reflorestamento de áreas degradadas, de preservação permanente e em plantios mistos, por conta do rápido crescimento 
inicial (ARAÚJO; PAIVA, 2011). Em 2011, foi realizada e publicada uma pesquisa (BARRETTO e FERREIRA, 2011) referente aos aspectos morfológicos da espécie do presente estudo, porém ainda existem pontos importantes a elucidar durante a germinação e o desenvolvimento pós-seminal.

Outra questão refere-se às Instruções para a Análise de Sementes de Espécies Florestais, o qual não descreve de forma clara as características de uma plântula normal forte desta espécie, informação esta importante para avaliação em exames laboratoriais.

\section{Metodologia}

O trabalho foi desenvolvido no Laboratório de Sementes Florestais da Unidade Acadêmica Especializada em Ciências Agrárias, pertencente à Universidade Federal do Rio Grande do Norte, no município de Macaíba-RN.

As sementes utilizadas nesta etapa foram adquiridas de cinco lotes, provenientes de matrizes distintas e de diferentes procedências e épocas de coletas, com o objetivo de obter variabilidade genética e diferença na qualidade fisiológica que possibilitassem ao estudo abranger o máximo de variações morfológicas entre as plântulas.

Para a caracterização morfológica das plântulas, foram colocadas para germinar 100 sementes, em quatro repetições de 25 sementes cada. Com o intuito de acompanhar o completo desenvolvimento do processo germinativo e do crescimento inicial de plântula, o ensaio foi conduzido no sistema de rolos de papel toalha (tipo Germitest ${ }^{\circledR}$ ) e em bandejas com areia previamente lavada e esterilizada. As sementes utilizadas foram adquiridas de uma amostragem composta de seis lotes disponibilizados pela Floresta Nacional de Nísia Floresta - FLONA.

As mesmas passaram pelo processo de assepsia e superação de dormência (BRASIL, 2013). Após, foram semeadas e condicionadas em germinador do tipo Biochemical Oxigen Demand (B.O.D.) à temperatura de $25^{\circ} \mathrm{C}$ e fotoperíodo de 12 horas.

O processo germinativo das sementes foi descrito através de avaliações diárias e registro de imagens. As plântulas foram classificadas conforme o proposto por Miquel (MIQUEL, 1987; GURGEL et al., 2012), sendo diferenciadas quanto à posição dos cotilédones na germinação, o tipo de cotilédone e a persistência do tegumento. As colorações das estruturas foram descritas com referência na carta de coloração de Munsell.

Foi realizada a caracterização completa das estruturas essenciais de uma plântula, tais como: descrição da parte radicular, parte aérea (hipocótilo, cotilédones, epicótilo e eófilos). Foram descritos para cada das estruturas o tamanho médio $(\mathrm{cm})$, formato, coloração, posição da estrutura na plântula e presença de pelos, estrias e lenticelas. 
As plântulas foram caracterizadas como normais, a partir da identificação de suas estruturas (SOUZA, 2009). As plântulas que apresentaram suas estruturas essenciais danificadas, deformadas, deterioradas, ou plântulas albinas foram classificadas como anormais (BRASIL, 2013). Ao fim da avaliação $\left(14^{\circ}\right.$ dia) foi descrita a morfologia para a espécie Enterolobium contortisiliquum.

\section{Resultados e Discussão}

Desenvolvimento de plântulas - Após 24 horas da semeadura, as sementes encontravam-se intumescidas; a emissão de raiz primária ocorreu no quarto dia (96 horas) após a semeadura, com coloração 5Y 8/1 (cinza claro), rompendo o tegumento na base da semente, próximo ao hilo; a partir do sexto dia, foi possível observar a diferenciação morfológica entre a estrutura radicular e parte aérea; a raiz primária pivotante $(3,5-10,5 \mathrm{~cm})$ mostrou-se de coloração 2.5 Y 8/4 (amarelo claro), sinuosa, flexuosa e com presença de pelos simples, poucos visíveis e esparsos, também foi obsevada a presença de coifa (Figura 1); ao fim (14 dias) da avaliação notaram-se poucas raízes secundárias (Figura 2).

Não foi descrita a presença de coifa para a espécie no trabalho realizado por Barretto e Ferreira (2011). A coifa é uma estrutura que envolve o ápice da raiz e protege o meristema do atrito com o substrato (GONÇALVES; LORENZI, 2007).

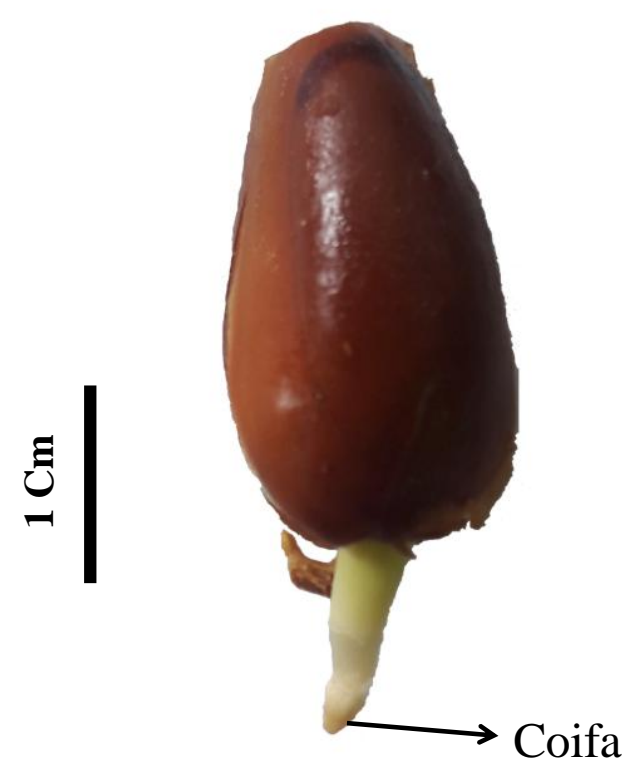

Figura 1: Desenvolvimento radicular da espécie da Enterolobium contortisiliquum, ilustrando a presença de coifa.

A partir do sexto dia, os cotilédones emergiram acima do nível do substrato. A partir do sétimo dia ocorreu o desprendimento do tegumento, deixando os cotilédones carnosos livres, evidenciando uma germinação do tipo epígea fanerocotiledonar. Os cotilédones são de coloração 
7.5 GY 5/4 (verde acinzentado amarelo), sem nervuras aparentes quando rompem o tegumento, são opostos, unilaterais, isófilos; têm variação de tamanho entre 1,5-2,3 cm de comprimento e de 0,91,2 $\mathrm{cm}$ de largura (Figura 2).

O tipo de germinação epígea fanerocotiledonar é a mais comum em várias espécies de leguminosas (SILVA et al, 2008). Outros autores descreveram em trabalhos semelhantes realizados com espécies pertencentes à família Fabaceae o tipo de epígea fanerocotiledonar: Erythrina speciosa (OLIVEIRA, 2001), Senna multijuga (AMORIM et al., 2008) e Guibourtia hymenifolia (BATTILANI et al, 2011).

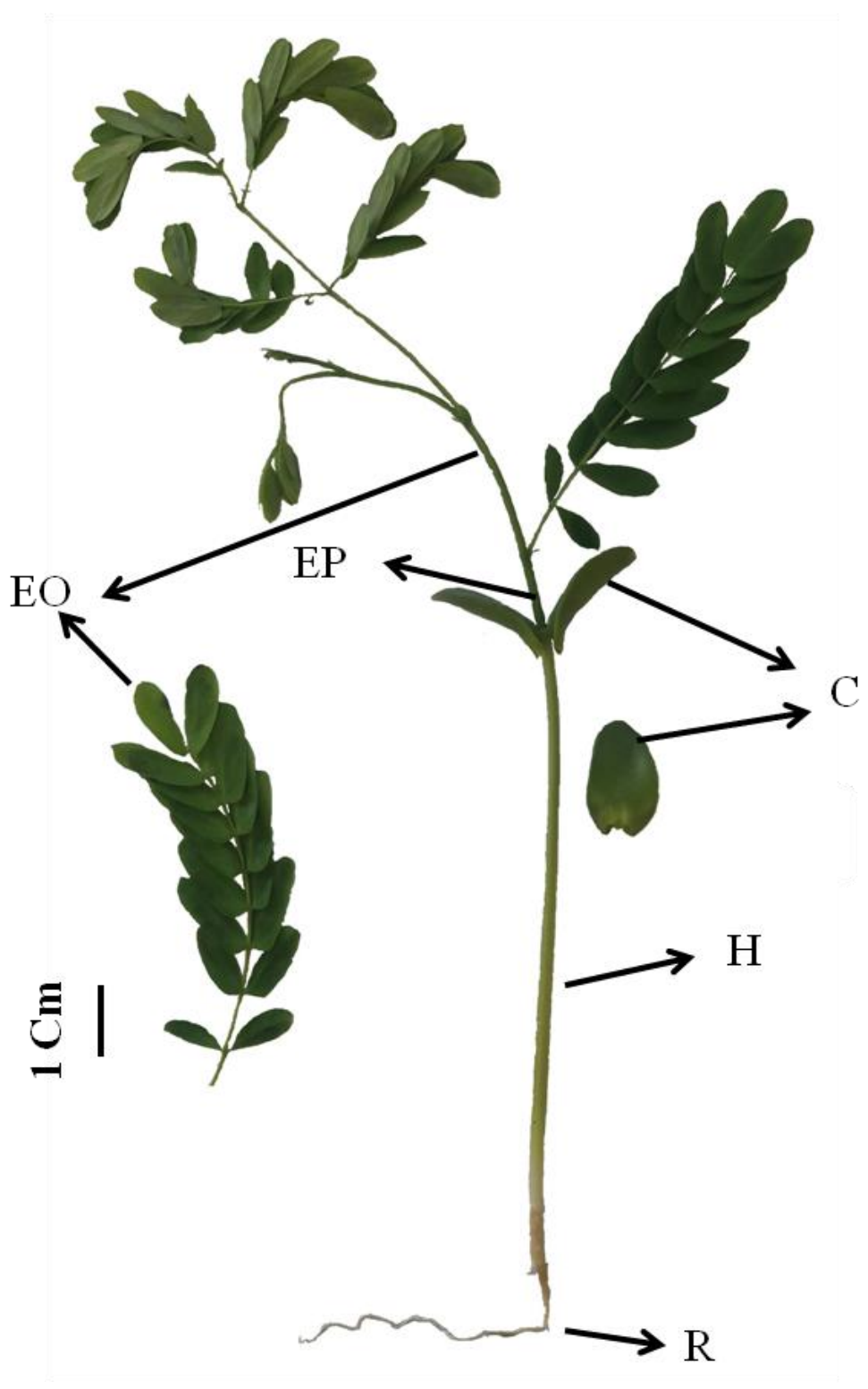

Figura 2: Plântula normal forte de Enterolobium contortisiliquum em que: R: raiz primária; T: tegumento; C: cotilédones; H: hipocótilo; EP: epicótilo e EO - eófilo. 
O hipocótilo é alongado variando de 9,0 a $12,8 \mathrm{~cm}$ de comprimento, retilíneo, com coloração variando $2.5 \mathrm{GY} \mathrm{6/4} \mathrm{(verde} \mathrm{acinzentado} \mathrm{amarelo} \mathrm{claro),} \mathrm{cilíndrico} \mathrm{e} \mathrm{sem} \mathrm{a} \mathrm{presença} \mathrm{de}$ pelos (Figura 2).

O epicótilo, visível a partir do $9^{\circ}$ dia após a semeadura, menos desenvolvido que o hipocótilo, apresentou variação no comprimento de 1,5 - 2,4 cm, também com a coloração $2.5 \mathrm{GY}$ 6/4 (verde acinzentado amarelo) (Figura 2).

Os eófilos são compostos, opostos, bipinados (3,5 a 5,5 de comprimento), com folíolos (10 a 12) variando $0,8-1,5 \mathrm{~cm}$ de comprimento e de $0,3-0,1 \mathrm{~cm}$ de largura, possuem $10 \mathrm{GY} 4 / 2$ (verde acinzentado amarelo escuro), com formato oblongo e borda (Figura 2).

Algumas espécies podem apresentar uma característica chamada de heterofilia, ou seja, a espécie apresenta morfologia distinta entre os eófilos (primeiras folhas) e as folhas de uma planta adulta, este evento não ocorre para a espécie Enterolobium contortisiliquum.

O conhecimento morfológico das estruturas de uma plântula (forma do limbo, da margem, do ápice de folhas, posição dos eófilos, presença de substâncias como resina ou látex, relação comprimento/ largura dos cotilédones, tamanho e número de pinas, presença ou não de indumento como tricomas e/ou glândulas e etc) permite caracterizar famílias, gêneros e até mesmo espécies (DUKE, 1965; GURGEL et al., 2012).

\section{Conclusões}

A germinação e o crescimento inicial das plântulas de Enterolobium contortisiliquum foram homogêneos, o que possibilita a confiabilidade nos dados, possibilitando o uso tanto na identificação em campo quanto em testes laboratoriais.

A raiz apresenta coifa e o uso da morfometria da plântula complementa estudos morfológicos sobre a espécie.

\section{Referências}

AMORIM, I. L. DAVIDE, A. C.; FERREIRA, R. A.; CHAVES, M. M. F. Morfologia de frutos, sementes, plântulas e mudas de Senna multijuga var. lindleyana (Gardner) H. S. Irwin \& Barneby Leguminosae Caesalpinioideae. Revista Brasileira Botânica, São Paulo, v. 31, n. 3, p. 507-516. 2008.

ARAÚJO, A. P.; PAIVA, S. Germinação e produção de mudas de tamboril (Enterolobium Contortisiliquum (Vell.) Morong) em diferentes substratos. Revista Árvore, [s.1.], v. 35, n. 31, p.581-588, jun. 2011. 
BARRETTO, S. S. B.; FERREIRA, R. A.. Aspectos morfológicos de frutos, sementes, plântulas e mudas de leguminosae mimosoideae: Anadenanthera colubrina (vellozo) brenan e Enterolobium contortisiliquum (vellozo) morong. Revista Brasileira de Sementes, [s.1.], v. 33, n. 2, p.223-232, 2011.

BATTILANI, J. L.; SANTIAGO, E. F.; E DIAS, E. S. Morfologia de frutos, sementes, plântulas e plantas jovens de Guibourtia hymenifolia (Moric.) J. Leonard (Fabaceae). Revista Árvore, Viçosa, v. 35, n. 5, p. 1089-1098, 2011.

BRASIL. Ministério da Agricultura, Pecuária e Abastecimento. Instruções para Análises de Sementes de Espécies florestais. Ministério da Agricultura, Pecuária e Abastecimento. Secretaria de Defesa Agropecuária. Brasília: MAPA/ACS, 2013.

FEITOZA, G. V.; SANTOS, J. U. M.; GURGEL, E. S. C.; OLIVEIRA, D. M. T. Morphology of fruits, seeds, seedlings and saplings of three species of Macrolobium Schreb. (Leguminosae, Caesalpinioideae) in the Brazilian Amazon floodplain. Revista Acta Botanica Brasilica, v. 28, n. 3, p.422-433, set. 2014.

FERREIRA, A. G.; BORGHETTI, F.. Germinação: Do básico ao aplicado. Porto Alegre: Artmed, 2004.

GONÇALVES, E. G.; LORENZI, H. Morfologia Vegetal: Organografia e dicionário inlustrado de morfologia das plantas vasculares. São Paulo: Câmara Brasileira do Livro, 2007. 401 p

GURGEL, E. S. C.; SANTOS, J. U. M.; LUCAS, F. C. A.; BASTOS, M. N. C. Morfologia de plântulas de Leguminosae e o potencial sistemático. Rodriguésia: revista do jardim botânico do rio de janeiro, v. 63, n. 1, p.65-73, 2012.

MENDONÇA, A. V. R. Freitas, T. A. S.; Souza, L. S.; Fonseca, M. D. S.; Souza, J. S. MORFOLOGIA DE FRUTOS E SEMENTES E GERMINAÇÃO DE Poincianella pyramidalis (Tul.) L. P. Queiroz, comb. Nov. Ciência Florestal, [s.1.], v. 26, n. 2, p.375-387, 20 jun. 2016. MMA - MINISTÉRIO DO MEIO AMBIENTE. Manejo Sustentável dos Recursos Florestais da Caatinga. Natal-RN: MMA, 2008. 28 p.

OLIVEIRA, D. M. T. Morfologia comparada de plântulas e plantas jovens de leguminosas arbóreas nativas: espécies de Phaseoleae, Sophoreae, Swartzieae e Tephrosieae. Revista Brasileira Botânica. São Paulo, v. 24, n. 1, p. 85-97, 2001. 
PIMENTA, A.C.; REGO, S.S.; ZUFFELlATO-RIBAS, K.C.; NOGUEIRA, A.C.; KOELHER, H.S. Morphological characterization of fruits, seeds and seedlings of araticum plant (Annona crassiflora Mart - Annonaceae). Journal of Seed Science, v. 35, p. 524-531, 2013.

RIZZINI, Carlos Toledo. Árvores e madeiras úteis do Brasil: Manual de dendrologia brasileira. 2. ed. São Paulo: Edgard Blucher Ltda, 1978. 296 p.

SILVA, K. B.; ALVES, E. U.; BRUNO, R. L. A.; MATOS, P. V.; GONÇALVES, E. P. Morfologia de frutos, sementes, plântula e plantas de Erytrhina velutina Willd. Leguminoseae - Papilionideae. Revista Brasileira de Sementes, v. 30, n. 3, p. 104-114, 2008. 